\title{
1 Innovations to expand drone data collection and analysis for rangeland 2 monitoring
}

3

4

5

6

7
Jeffrey K. Gillan ${ }^{1 \dagger}$, Guillermo E. Ponce-Campos ${ }^{1}$, Tyson L. Swetnam², Alessandra Gorlier ${ }^{1}$, Philip Heilman ${ }^{3}$, and Mitchel P. McClaran ${ }^{1}$

${ }^{1}$ University of Arizona

School of Natural Resources \& Environment

1064 East Lowell Street

Tucson, AZ 85721

${ }^{2}$ University of Arizona

BIO5 Institute

1657 East Helen Street

Tucson, AZ 85721

${ }^{3}$ USDA Agricultural Research Service

Southwest Watershed Research Center

2000 East Allen Road

Tucson, AZ 85719

${ }^{\dagger}$ Corresponding Author

Jeffrey K. Gillan

Email: jgillan@email.arizona.edu

Data, including raw imagery, point clouds (.laz \& Entwine Point Tiles), digital surface models, digital terrain models, vegetation height models, and orthomosaics, and software code will be made available in Cyverse Data Commons through a stable DOI. This link is currently where the data resides and will get a permanent stable address once published.

https://datacommons.cyverse.org/browse/iplant/home/shared/aes/srer/suas/2019/ecostate_mapping

Python, R, HTML, and Google Earth Engine code used in this project can also be found at:

https://github.com/jeffgillan/Drone-Imagery-Analysis 


\section{Abstract}

42 In adaptive management of rangelands, monitoring is the vital link that connects management actions

43 with on-the-ground changes. Traditional field monitoring methods can provide detailed information for

44 assessing the health of rangelands, but cost often limits monitoring locations to a few key areas or

45 random plots. Remotely sensed imagery, and drone-based imagery in particular, can observe larger

46 areas than field methods while retaining high enough spatial resolution to estimate many rangeland

47 indicators of interest. However, the geographic extent of drone imagery products is often limited to a

48 few hectares (for resolution $\leq 1 \mathrm{~cm}$ ) due to image collection and processing constraints. Overcoming

49 these limitations would allow for more extensive observations and more frequent monitoring. We

50 developed a workflow to increase the extent and speed of acquiring, processing, and analyzing drone

51 imagery for repeated monitoring of two common indicators of interest to rangeland managers:

52 vegetation cover and vegetation heights. By incorporating a suite of existing technologies in drones

53 (real-time kinematic GPS), data processing (automation with Python scripts, high performance

54 computing), and cloud-based analysis (Google Earth Engine), we greatly increased the efficiency of

55 collecting, analyzing, and interpreting high volumes of drone imagery for rangeland monitoring. End-to-

56 end, our workflow took 30 days, while a workflow without these innovations was estimated to require

57141 days to complete. The technology around drones and image analysis is rapidly advancing which is

58 making high volume workflows easier to implement. Larger quantities of monitoring data will

59 significantly improve our understanding of the impact management actions have on land processes and

60 ecosystem traits.

61

\section{Keywords}

63 Unmanned aerial systems, high performance computing, cloud computing, RTK, monitor 
Introduction

The rangeland manager's challenge is the extensive management across a heterogeneous landscape under an uncertain climate. With so much uncertainty, rangeland managers typically opt for an adaptive management approach, particularly in the public domain rangelands that dominate the western US. Adaptive management is not simply trial and error, but according to the Department of Interior (Williams et al., 2009): An adaptive approach involves exploring alternative ways to meet management objectives, predicting the outcomes of alternatives based on the current state of knowledge, implementing one or more of these alternatives, monitoring to learn about the impacts of management actions, and then using the results to update knowledge and adjust management actions. Unfortunately, budgetary and institutional constraints have long limited public land monitoring, as noted by FernandezGimenez et al. (2005). Sayre et al. (2013) state that monitoring is a critical component of adaptive management but often weak or missing in practice. The premise of this paper is that expanded

77 monitoring is a prerequisite for improved rangeland management. assessing the health of rangelands. Cost, however, often limits monitoring locations to a few key areas

81 or random plots that observe a small fraction of the land they are intended to represent (Booth and Cox, 82 2011; Toevs et al., 2011; West, 2003). Remotely sensed imagery enables a broader view of the land and 83 potentially a more representative sample. Drone-based imagery, in particular, can observe larger areas

84 than field methods while retaining high enough spatial resolution to estimate many rangeland indicators

85 of interest. These indicators include vegetation cover (Baena et al., 2017; Breckenridge et al., 2011;

86 Hardin et al., 2007; Laliberte and Rango, 2011), vegetation heights (Cunliffe et al., 2016; Gillan et al., 87 2020; Jensen and Mathews, 2016; Olsoy et al., 2018), biomass (Cunliffe et al., 2016; Michez et al., 2019), 
forage utilization (Gillan et al., 2019), and soil erosion (D'Oleire-Oltmanns et al., 2012; Gillan et al.,

89

90

91

92 2017). (SfM-MVS) is a low-cost workflow capable of meeting several rangeland monitoring needs. However, challenges remain to deploy this technology at larger operational scales. The geographic extent of drone magery products is often limited to a few hectares (for spatial resolution $\leq 1 \mathrm{~cm}$ ) due to image collection and processing constraints. Additionally, sharing data and reporting out monitoring results to collaborators and stakeholders can be limited by large file sizes and the complexity of web development. Overcoming these limitations would move us closer to realizing the potential value of drone-based monitoring, which is: 1 . broader extent observations; 2 . better measurement of some indicators; and 3. permanent visual records. Scaling the production and interpretation of drone imagery will be essential to support adaptive management on individual allotments as well as to integrate with national-scale monitoring programs such as the Bureau of Land Management's Assessment, Inventory, and Monitoring (AIM) strategy and the Natural Resource Conservation Service's National Resource Inventory (NRI).

\footnotetext{
111 use of drone imagery for mapping ecological states (Steele et al., 2012).
} 
Methods

114 Study Area

115 We conducted this research at Santa Rita Experimental Range (SRER) in southern Arizona $\left(31^{\circ} 48^{\prime} 36^{\prime \prime} \mathrm{N}\right.$, $116110^{\circ} 50^{\prime} 51^{\prime \prime}$ W; Fig. 1). The range, established in 1902 , is a 21,000 ha Sonoran Desert grassland that has

117 been significantly invaded by velvet mesquite (Prosopis velutina). SRER is a living laboratory for studying

118 dryland ecology and sustainable livestock production. The range has over 200 permanent long-term

119 transects intended to capture vegetation dynamics across multi-decadal time spans (McClaran et al.,

120 2002; cals.arizona.edu/srer). In the upper elevations of the range (1050-1300 m MSL; Major Land

121 Resource Area 41-3), we selected a subset of 100 transects for this study. The long-term transect

122 locations are not randomized and thus do not represent an unbiased sample of the study area. It was

123 not our intent to extrapolate results to monitor all of SRER. Instead, the legacy transect locations

124 provided a large sample size from which to demonstrate our workflow.

Image Acquisition

127 We collected drone imagery covering the 100 transects in May 2019 (dry season) and repeated the

128 acquisition in September 2019 (monsoon season). We used a DJI Phantom 4 RTK quadcopter specifically

129 because it possessed a real-time kinematic global navigation satellite system (RTK GNSS). RTK GNSS on

130 drones is not a new technology, but it is now more accessible due to its integration in off-the-shelf

131 aircraft at reduced cost. The Phantom 4 RTK in 2019 cost $\sim \$ 8,000$ and came paired with a portable GNSS

132 base station and tripod (D-RTK 2).

134 RTK is a technology that pinpoints the 3D coordinates of the camera for each image taken from the 135 moving drone. It can be accurate within a few centimeters, which is more precise than a typical global 
positioning system (GPS) receiver is. RTK GNSS is a differential correction system where the aircraft is in

137 constant communication with a nearby portable base station with known coordinates (i.e., placed over a

138 surveyed benchmark). When an image is taken, the location of the drone (and more specifically the

139 camera), as estimated from the onboard GPS, is compared with and corrected by a signal from the base

140 station. The improved location coordinates (i.e., latitude, longitude, elevation) are then recorded as

141 metadata on the exchangeable image format (EXIF) header of each image.

143 Highly accurate camera locations can replace the use of ground control points (GCPs) to scale and

144 georeference imagery products such as point clouds and orthomosaics (Forlani et al., 2018; Hugenholtz

145 et al., 2016; Rehak et al., 2013). RTK allowed us to streamline two aspects of the workflow. First, it

146 eliminated the need to place and survey GCPs with either a total station or ground-based differential

147 GPS. It can be quite cumbersome to survey GCPs, especially for large flight areas that may require a

148 dozen or more. Second, labor was eliminated in the photogrammetry processing step of identifying each

149 GCP in every image. Algorithms in commercial software aimed at automatically identifying GCPs are not

150 always successful, especially for oblique angle views. With RTK drones, we can collect and create high-

151 quality image products over large extents, while a GCP workflow practically limits us to plot scales.

153 Prior to this study, SRER had only one known surveyed benchmark. We established and surveyed more

154 benchmarks using a Trimble R10 RTK GNSS (base station and rover). We set the Trimble base station

155 over the original benchmark and roved across the range setting up new benchmark points near all of the

156 flight transects. Because of some transect clustering, we needed just 39 benchmarks to cover the 100

157 transects (Fig. 1). The benchmark points were existing rebar posts that marked the ends of long-term

158 transects. Absolute accuracy of the surveyed benchmarks was $<1 \mathrm{~cm}$ horizontal and $1-1.5 \mathrm{~cm}$ vertical. 
159 We used the drone portable base station (D-RTK 2) placed over the benchmarks to facilitate RTK

160 location correction while the drone flew and collected images.

161

162 Through our own independent assessment, we found the RTK drone imagery products (flown at $38 \mathrm{~m}$

163 above ground level) to have horizontal location accuracy of $2.2 \mathrm{~cm}$ and vertical accuracy of $3.4 \mathrm{~cm}$. This

164 was within $\sim 1 \mathrm{~cm}$, both horizontally and vertically, of an assessment conducted by DroneDeploy

165 (Mulakala, 2019). Our reproducibility assessment yielded a horizontal precision of $3 \mathrm{~cm}$ and vertical

166 precision of $<1 \mathrm{~cm}$ for digital surface models.

167

168 For each of the two campaigns (dry and wet seasons), we collected 53 flight plots to cover the 100

169 transects, a total of 193.1 ha (Fig. 1). Transects that were very near each other $(<300 \mathrm{~m})$ were often

170 captured in a single image product. Flight plots ranged in size from 1.6 to 7.1 ha to meet the objectives

171 of the ecological state mapping project. We collected a high density of nadir and oblique images ( 200

$172 \mathrm{ha}^{-1}$ ) in order to create very detailed and accurate point cloud models and downstream products such as

173 vegetation height models (VHMs). See Table 1 for full sensor and acquisition specifications and Fig. 2 for

174 a chart of the entire workflow.

176 Image Product Creation

177 Eliminating ground control points through the use of RTK enabled us to fully automate imagery product

178 creation with Python scripts. What would take an analyst a few hours to complete interactively (in

179 addition to the dense point cloud reconstruction time), was scripted in Agisoft Metashape 1.5.2

180 (www.agisoft.ru). The general SfM-MVS workflow is well documented so it will be abbreviated here (see

181 Eltner et al., 2015; Smith et al., 2015; Snavely et al., 2008; Westoby et al., 2012). Python scripts, running

182 from command line, added imagery to the project, created the sparse point cloud, filtered poor quality 
points, optimized the sparse model, then generated dense point clouds, digital surface models, digital

terrain models, and orthomosaics (see Table 2 for processing parameters). When the plot completed, it seamlessly started the next plot. Image processing reports were later spot checked for quality assurance.

197 We had to purchase educational Metashape licenses for each processing node ( $\$ 500$ each). Our machine (hereafter as the PC) with two Intel Xeon CPUs (2.4 GHz; 16 logical processors each), two Nvidia GeForce GTX 1080 video cards (GPUs), and 256 GB RAM. 
207

208

209

210

211

212

213

214

215

216

217

218

219

220

221

222

223

224

225

226

227

228

229

230

model on a cell-by-cell basis using the Raster package in Rstudio. This was executed on the PC and took approximately 4 hours to complete. With a simple shell command (see

https://entwine.io/quickstart.html), we converted all of the .las point clouds to entwine point tile (EPT), a format that facilitates browser-based viewing of large point clouds. We uploaded all image products and raw imagery to Cyverse Data Commons (cyverse.org/data-commons/....pending DOI) for public access and long-term storage.

Image Product Analysis

As large drone imagery datasets outpace desktop computing power, new tools are needed for rapid analysis, visualization, and sharing. We used the cloud-based analysis platform Google Earth Engine

(GEE; earthengine.google.com) to derive additional value-added indicators from the imagery products.

GEE is a cloud-based geospatial analytics platform with access to large computational resources and two application programming interfaces (API), JavaScript and Python. These APIs provide a suite of raster analysis functions including several classification algorithms (Gorelick et al., 2017). Though it was built primarily for broad scale satellite imagery, it is free and can also handle very large drone datasets. A powerful feature of GEE is the ability to easily share JavaScript code and imagery assets between users, which can make imagery analysis collaborative.

We uploaded all orthomosaics from the May acquisition $(n=53)$ into GEE and then mosaicked them together to form a single large super-mosaic (19.3 billion pixels). We repeated these steps for the May VHMs, September orthomosaics, and September VHMs. We used red, green, and blue bands, vegetation heights, and a calculated green leaf algorithm $\left(\frac{G * 2-R-B}{G * 2+R+B}\right.$; Louhaichi et al. 2001) as input features to thematically classify the imagery with a machine learning classification tree algorithm (Breiman et al., 1984). We identified four cover classes as a simple demonstration of the tool and workflow: herbaceous 
231 vegetation, woody vegetation (including cactus), bare-ground, and shadow. We used the polygon

232 digitizing tool within GEE to select training data for each class. We generated seven training polygons for

233 each class, with each training polygon containing hundreds of training pixels. For classification

234 validation, we randomly selected 50 pixels for each class across the super-mosaic. These pixels were

235 visually interpreted and compared with their assigned class.

237 For comparison with a conventional workflow, we classified the drone imagery using ArcGIS Pro 2.5

238 (esri.com) installed on the PC. We used the same input features and basic training procedures as our

239 GEE workflow. Instead of merging all the orthomosaics into a super-mosaic (as we did in GEE), we used

240 Model Builder to automate the sequentially classification of each orthomosaic using the Random Trees

241 algorithm. We enabled parallel processing to use all available CPUs for faster classification.

244 For sharing monitoring results and image product visualization on the web, we chose two platforms. We

245 developed a public facing web-app directly in GEE that enables users to view the orthomosaics, VHMs,

246 classified maps, and see summaries of the vegetation cover and vegetation heights. The website was

247 developed with JavaScript and is served through Google Cloud. Additionally, we developed a mapping

248 application using Leaflet, an open-source JavaScript library (https://de.cyverse.org/....pending DOI).

249 Users are able to explore a map of all the flight plots at SRER. Clicking on individual plots invites users to

250 view high-resolution versions of the orthomosaics and 3D point clouds directly in their web browser. The

251 orthomosaics are displayed in Eox Cog Explorer (https://geotiffjs.github.io). The point clouds are

252 viewable using Potree (entwine.potree.io), a free open-source web graphics library that renders point

253 clouds directly in your web browser using the EPT format. 


\section{Results and Discussion}

257 By incorporating a suite of existing technologies in drones (RTK GNSS), data processing (automation with

258 Python scripts, high performance computing), and cloud-based analysis (Google Earth Engine), we

259 increased the efficiency of collecting, analyzing, and interpreting high volumes of drone imagery for

260 rangeland monitoring. End-to-end, our workflow took 30 days, while a workflow without these

261 innovations was estimated to require 141 days to complete (Table 3).

RTK saved us considerable time in the image collection step (Table 3). With a GCP workflow, small plots would require 5 to 8 GCPs, and larger plots could require 10 to 20 GCPs to achieve accuracies comparable to the RTK results (James et al., 2017; Sanz-Ablanedo et al., 2018). A conservative estimate would be 300 GCPs for all of the flight plots, which could take upwards of 30 workdays to install and survey. Our RTK workflow, for comparison, required just 3 days to survey 39 benchmarks at existing stakes. Placing and collecting GCP targets before and after the flights would add an additional 30 minutes to each plot. This could push the total number of flying days from 12 (with RTK) to 16. Our RTK workflow eliminated the manual labor of identifying GCPs during the image processing step, which could

271 take hours per plot. We estimated a savings of 20 workdays by eliminating manual GCP identification.

273 Other potentially more efficient options for image product referencing exist. For example, cellular tower

274 virtual reference systems can send correction signals to flying drones using tablets or smartphone

275 devices as an intermediary. These correction networks could eliminate our need to use portable base

276 stations and surveyed benchmarks. In Southern Arizona, a private company provides the correction

277 signal as a service, but we decided against this option because strong cellular reception was not reliable

278 everywhere in the study area. As cellular coverage expands, even across rural rangelands, virtual 
reference systems will become increasingly viable for drone image product referencing. Alternatively,

the drone and portable base station workflow used in this project could be executed without surveying products are correctly scaled but may be shifted horizontally or vertically from a true absolute position

284 (see Gillan et al., 2020).

The HPC was 14 to $24 x$ faster than the PC at dense point cloud reconstruction, depending on the

PC, was completed in 1.6 hours on the HPC. A 1500 image plot that took 120 hours to process on the PC,

days. 
304 Classifying all drone orthomosaics in GEE was essentially instant. Near instant feedback allowed us to quickly assess classification results and adjust training data for higher accuracy (see Appendix Tables S1

\& S2 for confusion matrices). In comparison, it took 3 hours to classify 53 orthomosaics using ArcGIS

Pro on the PC.

GEE worked well for classifying the imagery and is currently the most mature tool for quickly analyzing large quantities of drone imagery. However, limitations of the platform include data storage limits and upload/download speeds to and from GEE. Additionally, it has limited functionality to conduct every

312 analysis we might want for rangeland monitoring (e.g., 3D point cloud analysis; landscape metrics). A

313 greater variety of analysis options exist in ArcGIS Pro, but they may be less accessible to users due to 314 cost. Fortunately, there is an enormous and growing variety of image analysis tools available across open platforms such as R, Python, and QGIS. Many have the capability to maximize local computing resources and distribute processing tasks to HPC clusters (see parallel processing options for $\underline{R}$ and

317 Python). The availability of high throughput analysis tools will soon not be a constraint. Instead, the 318 challenge will be to identify workflow 'best practices' for estimating a suite of rangeland indicators and selecting the best mix of tools that are cost-effective and repeatable (Gillan et al., 2020).

321 Leaflet paired with Exx COG Explorer and Potree provided an easy-to-build web map for visualizing the 322 point cloud and orthomosaic products (Fig. 4; https://de.cyverse.org/....pending DOI). The Potree viewer 323 has basic analysis tools (distance, volume, profile). The GEE app enabled us to share the classified maps, 324 VHMs, and graphed summaries of vegetation cover and heights (Fig. 5; https://bit.ly/srer-drone-2019). 325 Both of these sharing options eliminated the need for collaborators to download large files or install $3^{\text {rd }}$ 326 party software on their local machines. 


\section{Implications}

329 High volume drone imagery will enable us to move beyond 'proofs of concept' and other small-scale

330 research demonstrations to data quantities that significantly improve our understanding of land

331 processes. In an adaptive management framework, this means expanding monitoring beyond the

332 confines of plots and transects to provide a more representative sample of vegetation characteristics

333 across rangelands. A more representative sample could increase the statistical power to detect indicator

334 change by either increasing the sample size (i.e., collecting imagery at more locations than transects), or

335 by expanding the observational area of each transect to reduce variance between samples (Sundt,

336 2002). Our drone imagery covered 193 ha during the dry and wet seasons each representing $1.3 \%$ of

337 MLRA 41-3 at SRER. For comparison, the 100 permanent field transects (with length of $30.48 \mathrm{~m}$ and

338 width of $0.3 \mathrm{~m}$ ) observes a total of 0.09 ha which is only $0.00006 \%$ of MLRA $41-3$ at SRER.

340 The economies of scale provided by high volume drone imagery could be an appealing dataset to

341 supplement field data collected for national-scale monitoring programs such as BLM AIM and NRI (Gillan

342 2020). Though it has limited ability to distinguish grass and forb species, drone imagery can expand

343 generalized estimates of vegetation cover, provide a more robust measure of vegetation heights, and

344 enable the development of landscape metrics not measurable from the ground. Additionally, drone

345 imagery estimates of vegetation cover can be 'upscaled' to satellite imagery to cover vast landscapes

346 (Elkind et al., 2019; Holifield-Collins et al., 2020).

348 All of the technologies described in this paper are available to most range practitioners in the US.

349 Though there are some current barriers related to cost (drone equipment and software licenses), cyber

350 infrastructure, and technical expertise, these barriers are dissolving. Drone technology and image 
351 processing software are advancing and becoming cheaper. HPC, though still housed primarily at

352 universities and government agencies, is becoming more common and available to outside users (via

353 web portals). Remote sensing specialists or data scientists should carry out our innovative workflow but

354 the results and imagery products can easily by shared with less technical collaborators and stakeholders.

Conclusion

357 We demonstrated a workflow to increase the efficiency of collecting, processing, and analyzing large 358 volumes of drone imagery for rangeland monitoring applications. Our innovative workflow saved an 359 estimated 111 workdays compared with a conventional approach. These cost savings make more 360 practical a rich stream of monitoring data from which to link ecosystem traits with management actions. 361 The technological barriers surrounding the use of drone imagery are quickly dissolving which will foster 362 wider adoption by those who study and manage public rangelands.

365 This material is based upon work supported by the U.S. Department of Agriculture, Agricultural Research

366 Service, under Agreement No. 58-2022-5-13. This research was a contribution from the Long-Term

367 Agroecosystem Research (LTAR) network. LTAR is supported by the U.S. Department of Agriculture. Any opinions, findings, conclusion, or recommendations expressed in this publication are those of the

369 author(s) and do not necessarily reflect the view of the U.S. Department of Agriculture.

371 Mention of a proprietary product does not constitute a guarantee or warranty of the products by the

372 U.S. Government or the authors and does not imply its approval to the exclusion of other products that

373 may be suitable. 
375 The authors declare no conflicts of interest.

376

\section{Literature Cited}

381
Baena, S., Moat, J., Whaley, O., Boyd, D.S., 2017. Identifying species from the air: UAVs and the very high resolution challenge for plant conservation. PLoS One 12, e0188714. https://doi.org/10.1371/journal.pone.0188714

Booth, D., Cox, S., 2011. Art to science: Tools for greater objectivity in resource monitoring. Rangelands 33, 27-34. https://doi.org/10.2111/1551-501x-33.4.27

Breckenridge, R.P., Dakins, M., Bunting, S., Harbour, J.L., White, S., 2011. Comparison of Unmanned Aerial Vehicle Platforms for Assessing Vegetation Cover in Sagebrush Steppe Ecosystems. Rangel. Ecol. Manag. 64, 521-532. https://doi.org/10.2111/REM-D-10-00030.1

Breiman, J., Friedman, J., Olshen, R., Stone, C., 1984. Classification and regression trees. Chapman and Hall.

Cunliffe, A.M., Brazier, R.E., Anderson, K., 2016. Ultra-fine grain landscape-scale quantification of dryland vegetation structure with drone-acquired structure-from-motion photogrammetry. Remote Sens. Environ. 183, 129-143. https://doi.org/10.1016/j.rse.2016.05.019

D’Oleire-Oltmanns, S., Marzolff, I., Peter, K., Ries, J., 2012. Unmanned Aerial Vehicle (UAV) for Monitoring Soil Erosion in Morocco. Remote Sens. 4, 3390-3416. https://doi.org/10.3390/rs4113390

Elkind, K., Sankey, T.T., Munson, S.M., Aslan, C.E., 2019. Invasive buffelgrass detection using high- 
resolution satellite and UAV imagery on Google Earth Engine. Remote Sens. Ecol. Conserv.

rse2.116. https://doi.org/10.1002/rse2.116

400

Eltner, A., Kaiser, A., Castillo, C., Rock, G., Neugirg, F., Abellan, A., 2015. Image-based surface

401 reconstruction in geomorphometry - merits, limits and developments of a promising tool for geoscientists. Earth Surf. Dyn. Discuss. 3, 1445-1508. https://doi.org/10.5194/esurfd-3-1445-2015

Fernandez-Gimenez, M.E., McClaran, S.J., Ruyle, G., 2005. Arizona permittee and land management agency employee attitudes toward rangeland monitoring by permittees. Rangel. Ecol. Manag. 58, 344-351. https://doi.org/ht10.2111/1551-5028(2005)058[0344:APALMA]2.0.CO;2

Forlani, G., Dall'Asta, E., Diotri, F., Cella, U.M. di, Roncella, R., Santise, M., 2018. Quality Assessment of DSMs Produced from UAV Flights Georeferenced with On-Board RTK Positioning. Remote Sens. 10,

Gillan, J., Karl, J., Elaksher, A., Duniway, M., 2017. Fine-Resolution Repeat Topographic Surveying of and Precision against Traditional Ground-Based Erosion Measurements. Remote Sens. 9, 437.

Gillan, J.K., Karl, J.W., van Leeuwen, W.J.D., 2020. Integrating drone imagery with existing rangeland monitoring programs. Environ. Monit. Assess. 192, 269. https://doi.org/10.1007/s10661-020-8216-

Gillan, J.K., McClaran, M.P., Swetnam, T.L., Heilman, P., 2019. Estimating Forage Utilization with DroneBased Photogrammetric Point Clouds. Rangel. Ecol. Manag. 72, 575-585. https://doi.org/10.1016/j.rama.2019.02.009

419 Gorelick, N., Hancher, M., Dixon, M., Ilyushchenko, S., Thau, D., Moore, R., 2017. Google Earth Engine: $420 \quad$ Planetary-scale geospatial analysis for everyone. Remote Sens. Environ. 202, 18-27. 
422 Hardin, P., Jackson, M., Anderson, V., Johnson, R., 2007. Detecting Squarrose Knapweed ( Centaurea

423

424

425

426

427

428

429

430

431

432

433

434

435

436

437

438

439

440

441

442

443

444

445 virgata Lam. Ssp. squarrosa Gugl.) Using a Remotely Piloted Vehicle: A Utah Case Study. GIScience Remote Sens. 44, 203-219. https://doi.org/10.2747/1548-1603.44.3.203

Holifield-Collins, C., Skirvin, S., Winston, Z., Curley, D., Corrales, A., Armendariz, G., Gillan, J., Heilman, P., Metz, L., 2020. Improving a brush management assessment tool using drone technology and enhanced Landsat image processing, in: Society for Range Management Conference. Denver, CO.

Hugenholtz, C., Brown, O., Walker, J., Barchyn, T., Nesbit, P., Kucharczyk, M., Myshak, S., 2016. Spatial Accuracy of UAV-Derived Orthoimagery and Topography: Comparing Photogrammetric Models Processed with Direct Geo-Referencing and Ground Control Points. GEOMATICA 70, 21-30. https://doi.org/10.5623/cig2016-102

James, M.R., Robson, S., D’Oleire-Oltmanns, S., Niethammer, U., 2017. Optimising UAV topographic surveys processed with structure-from-motion: Ground control quality, quantity and bundle adjustment. Geomorphology 280, 51-66. https://doi.org/10.1016/j.geomorph.2016.11.021

Jensen, J.L.R., Mathews, A.J., 2016. Assessment of Image-Based Point Cloud Products to Generate a Bare Earth Surface and Estimate Canopy Heights in a Woodland Ecosystem. Remote Sens. 8. https://doi.org/10.3390/rs8010050

Laliberte, A.S., Rango, A., 2011. Image Processing and Classification Procedures for Analysis of Subdecimeter Imagery Acquired with an Unmanned Aircraft over Arid Rangelands. GIScience Remote Sens. 48, 4-23. https://doi.org/10.2747/1548-1603.48.1.4

Louhaichi, M., Borman, M.M., Johnson, D.E., 2001. Spatially Located Platform and Aerial Photography for Documentation of Grazing Impacts on Wheat. Geocarto Int. 16, 65-70. https://doi.org/10.1080/10106040108542184

McClaran, M.P., Angell, D.L., Wissler, C., 2002. Santa rita experimental range digital database: User's guide. USDA For. Serv. - Gen. Tech. Rep. RMRS-GTR 1-16. https://doi.org/10.2737/RMRS-GTR-100 
Michez, A., Lejeune, P., Bauwens, S., Lalaina Herinaina, A.A., Blaise, Y., Muñoz, E.C., Lebeau, F., Bindelle, J., 2019. Mapping and monitoring of biomass and grazing in pasture with an unmanned aerial system. Remote Sens. 11, 1-14. https://doi.org/10.3390/rs11050473

Mulakala, J., 2019. Measurement Accuracy of the DJI Phantom 4 RTK \& Photogrammetry.

Olsoy, P.J., Shipley, L.A., Rachlow, J.L., Forbey, J.S., Glenn, N.F., Burgess, M.A., Thornton, D.H., 2018. Unmanned aerial systems measure structural habitat features for wildlife across multiple scales. Methods Ecol. Evol. 9, 594-604. https://doi.org/10.1111/2041-210X.12919

Rehak, M., Mabillard, R., Skaloud, J., 2013. a Micro-Uav With the Capability of Direct Georeferencing. Int. Arch. Photogramm. Remote Sensing, Beijing, China XL, 4-6. https://doi.org/10.5194/isprsarchives-XL-1-W2-317-2013

Sanz-Ablanedo, E., Chandler, J., Rodríguez-Pérez, J., Ordóñez, C., Sanz-Ablanedo, E., Chandler, J.H., Rodríguez-Pérez, J.R., Ordóñez, C., 2018. Accuracy of Unmanned Aerial Vehicle (UAV) and SfM Photogrammetry Survey as a Function of the Number and Location of Ground Control Points Used. Remote Sens. 2018, Vol. 10, Page 1606 10, 1606. https://doi.org/10.3390/RS10101606

Sayre, N.F., Biber, E., Marchesi, G., 2013. Social and Legal Effects on Monitoring and Adaptive Management: A Case Study of National Forest Grazing Allotments, 1927-2007. Soc. Nat. Resour. 26, 86-94. https://doi.org/10.1080/08941920.2012.694579

Settlage, R., Chalker, A., Franz, E., Johnson, D., Gallo, S., Moore, E., Hudak, D., 2019. Open OnDemand: HPC for Everyone, in: Weiland, M., Juckeland, G., Alam, S., Jagode, H. (Eds.), High Performance Computing. Springer International Publishing, Cham, pp. 504-513.

Smith, M.W., Carrivick, J.L., Quincey, D.J., 2015. Structure from motion photogrammetry in physical geography. Prog. Phys. Geogr. 40, 247-275. https://doi.org/10.1177/0309133315615805

Snavely, N., Seitz, S.M., Szeliski, R., 2008. Modeling the world from Internet photo collections. Int. J. Comput. Vis. 80, 189-210. https://doi.org/10.1007/s11263-007-0107-3 
Steele, C.M., Bestelmeyer, B.T., Burkett, L.M., Smith, P.L., Yanoff, S., 2012. Spatially explicit representation of state-and-transition models. Rangel. Ecol. Manag. 65, 213-222. https://doi.org/10.2111/REM-D-11-00047.1

Sundt, P., 2002. The statistical power of rangeland monitoring data. Rangel. J. 24, 16-20. https://doi.org/10.2458/azu_rangelands_v24i2_sundt

Toevs, G.R., Karl, J.W., Taylor, J.J., Spurrier, C.S., Karl, M.S., Bobo, M.R., Herrick, J.E., 2011. Consistent Indicators and Methods and a Scalable Sample Design to Meet Assessment, Inventory, and Monitoring Information Needs Across Scales. Rangelands 33, 14-20. https://doi.org/10.2111/1551501X-33.4.14

West, N.E., 2003. Theoretical Underpinnings of Rangeland Monitoring. Arid L. Res. Manag. 17, 333-346. https://doi.org/10.1080/713936112

Westoby, M.J., Brasington, J., Glasser, N.F., Hambrey, M.J., Reynolds, J.M., 2012. 'Structure-fromMotion' photogrammetry: A low-cost, effective tool for geoscience applications. Geomorphology 179, 300-314. https://doi.org/10.1016/j.geomorph.2012.08.021

Williams, B.K., Szaro, R.C., Shapiro, C.D., 2009. Adaptive Management: the U.S. Department of the Interior Technical Guide. Adaptive Management Working Group, U.S. Department of the Interior, Washington, DC. 
bioRxiv preprint doi: https://doi org/10.1101/2021.02 05.430004 this version posted February 8, 2021. The copyright holder for this preprint (which was not certified by peer review) is the author/funder, who has granted bioRxiv a license to display the preprint in perpetuity. It is made available under aCC-BY-NC-ND 4.0 International license.

496

\begin{tabular}{|c|c|}
\hline Aircraft & DJI Phantom 4 RTK \\
\hline Sensor & $\begin{array}{l}20 \text { mpx; RGB; } \\
\text { Global Shutter }\end{array}$ \\
\hline Aperture \& Shutter & Automatic \\
\hline Image format & Jpeg; $\sim 8 \mathrm{mb} ; 8$ bit \\
\hline Autopilot & DJI GS RTK \\
\hline Acquisition Pattern & $\begin{array}{c}\text { Single Grid at Nadir; } \\
\text { Double Grid at } 30^{\circ} \text { Oblique }\end{array}$ \\
\hline Image forward \& side overlap & $80 \%$ \\
\hline Flying Height & $38 \mathrm{~m}$ above ground \\
\hline Flying Speed & $3 \mathrm{~m} / \mathrm{s}$ \\
\hline Flying time $h a^{-1}$ & $\sim 10$ min. \\
\hline Ground Sampling & $1 \mathrm{~cm}$ \\
\hline No. of Flight Plots & 53 \\
\hline Plot Sizes & $1.6-7.1$ ha \\
\hline Images Plot ${ }^{-1}$ & $278-1563$ \\
\hline Images ha-1 & $\sim 200$ \\
\hline Total Raw Imagery Size & $341 \mathrm{~GB}$ \\
\hline Total Image Product Size & $561 \mathrm{~GB}$ \\
\hline Total Area Imaged & 193.1 ha \\
\hline No. of Flying Days & 12 \\
\hline
\end{tabular}


bioRxiv preprint doi: https://doi.org/10.1101/2021.02.05.430004; this version posted February 8, 2021. The copyright holder for this preprint (which was not certified by peer review) is the author/funder, who has granted bioRxiv a license to display the preprint in perpetuity. It is made available under aCC-BY-NC-ND 4.0 International license.

507

508

\begin{tabular}{|c|c|}
\hline Parameter & Setting \\
\hline Photo Alignment & $\begin{array}{l}\text { Quality: Medium } \\
\text { Geometric Self-calibration: Yes } \\
\text { Generic Pre-selection: Yes } \\
\text { Reference Pre-selection: Yes } \\
\text { Adaptive Camera Model Fitting: Yes } \\
\text { Key point limit: } 50,000 \\
\text { Tie point limit: } 0\end{array}$ \\
\hline Camera Accuracy (m): & Long: 0.010; Lat:0.009; Alt: 0.021 \\
\hline Tie Point Accuracy (pix) & 0.3 \\
\hline $\begin{array}{l}\text { Poor Quality Point Removal } \\
\text { (using gradual selection) }\end{array}$ & $\begin{array}{l}\text { Reconstruction Uncertainty: }>13 \\
\text { Projection Accuracy: }>10 \\
\text { Reprojection Error: }>0.25\end{array}$ \\
\hline Camera Optimization & Adaptive Fitting: Yes \\
\hline Dense Point Cloud & $\begin{array}{l}\text { Quality: High } \\
\text { Filtering: Mild }\end{array}$ \\
\hline Point Filtering for DTM & $\begin{array}{l}\text { Select Ground Points by Color: } \mathrm{r} 255, \mathrm{~g} 220, \mathrm{~b} 178 \\
\text { Classify Ground Points: } \\
\text { Max angle: } 3.0^{\circ} \\
\text { Max distance: } 0.09 \mathrm{~cm} \\
\text { Cell size: } 4 \mathrm{~m}\end{array}$ \\
\hline DSM and DTM generation & $\begin{array}{l}\text { Point Cloud: Dense Cloud } \\
\text { Interpolation: Enabled }\end{array}$ \\
\hline Orthomosaic generation & $\begin{array}{l}\text { Blending Mode: Mosaic } \\
\text { Fill Holes: Yes } \\
\text { Surface: Sparse point cloud DEM } \\
\text { Images used: Nadir only } \\
\text { Spatial Resolution: } 1 \mathrm{~cm}\end{array}$ \\
\hline
\end{tabular}

511 Table 3. Number of workdays to collect, process, and analyze drone imagery collected in May 2019

\begin{tabular}{c|cccccc}
\hline & $\begin{array}{c}\text { Survey GCPs or } \\
\text { Benchmarks }\end{array}$ & $\begin{array}{c}\text { Collect } \\
\text { Imagery }\end{array}$ & $\begin{array}{c}\text { Identify } \\
\text { GCPs }\end{array}$ & $\begin{array}{c}\text { Image } \\
\text { Processing }\end{array}$ & $\begin{array}{c}\text { Orthomosaic } \\
\text { Classification }\end{array}$ & Total \\
$\begin{array}{c}\text { Conventional } \\
\text { Workflow } \\
\text { (estimate) }\end{array}$ & 30 & 16 & 20 & 75 & 0.35 & 141.35 \\
$\begin{array}{c}\text { Innovative } \\
\text { Workflow }\end{array}$ & 3 & 12 & 0 & 15 & 0 & 30
\end{tabular}


bioRxiv preprint doi: https://doi.org/10.1101/2021.02.05.430004: this version posted Februarv 8. 2021. The copvriaht holder for this preprint

(which was not certified by peer review) is the author/funder, who has granted bioRxiv a license to display the preprint in perpetuity. It is made available under aCC-BY-NC-ND 4.0 International license.


519 Fig. 1. A) This project occurred at Santa Rita Experimental Range (SRER) in southern Arizona. B) We collected aerial 520 imagery using a DJI Phantom 4 RTK with portable base station. C) We collected imagery at 53 flight plots covering a 521 total of 193 ha in May 2019 and repeated in September 2019. The drone was launched near surveyed benchmarks 522 (shown as red points).

523 
bioRxiv preprint doi: https://doi.org/10.1101/2021.02.05.430004; this version posted February 8, 2021. The copyright holder for this preprint (which was not certified by peer review) is the author/funder, who has granted bioRxiv a license to display the preprint in perpetuity. It is made available under aCC-BY-NC-ND 4.0 International license.

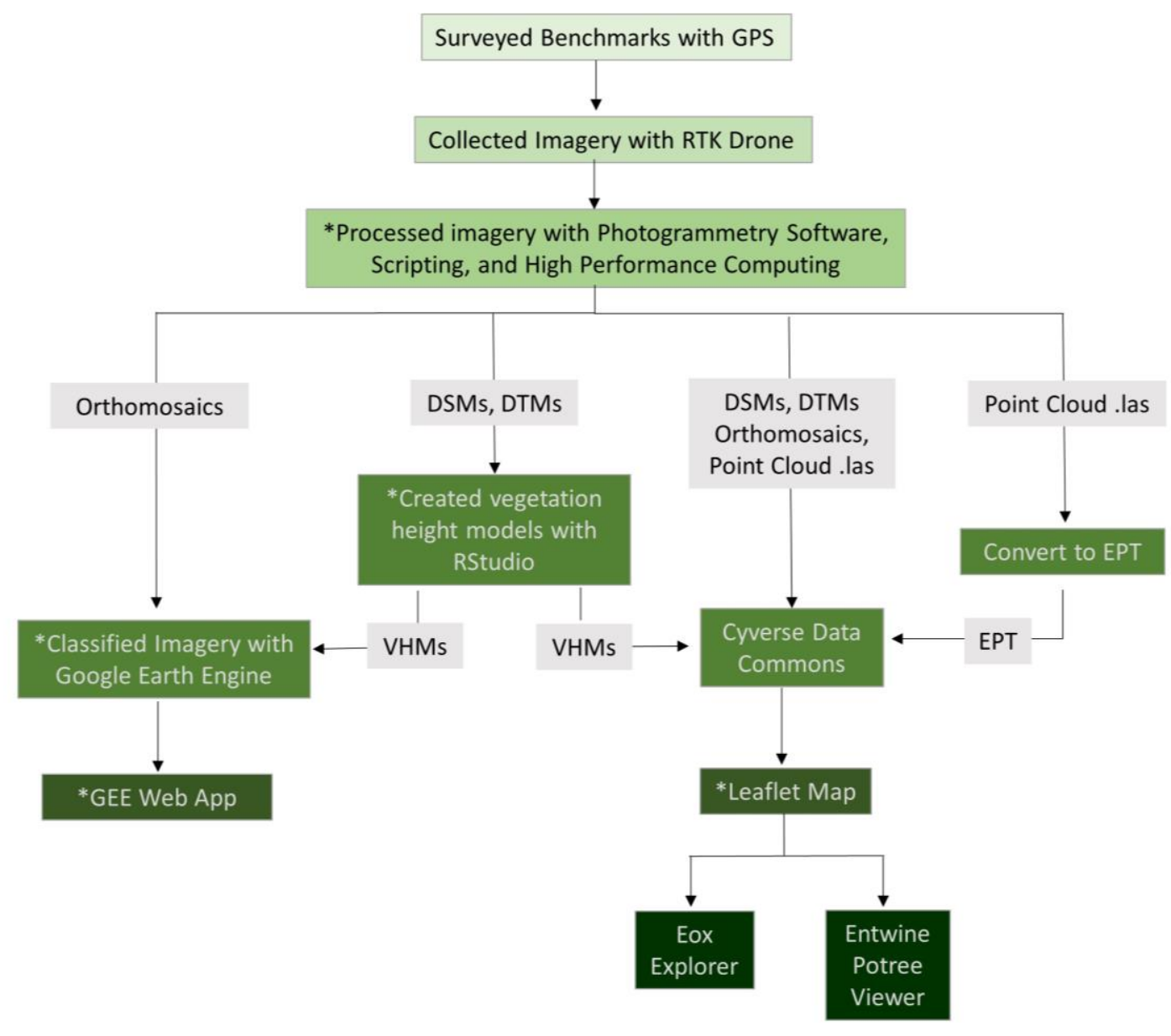

526 Fig. 2. Workflow for data collection, processing, and sharing. DSMs = digital surface models; DTMs = digital terrain 527 models; $V H M s=$ vegetation height models; EPT = entwine point tile. Items with ${ }^{*}$ have available code. 
bioRxiv preprint doi: https://doi.org/10.1101/2021.02.05.430004: this version posted Februarv 8. 2021. The copvriaht holder for this preprint (which was not certified by peer review) is the author/funder, who has granted bioRxiv a license to display the preprint in perpetuity. It is made available under aCC-BY-NC-ND 4.0 International license.
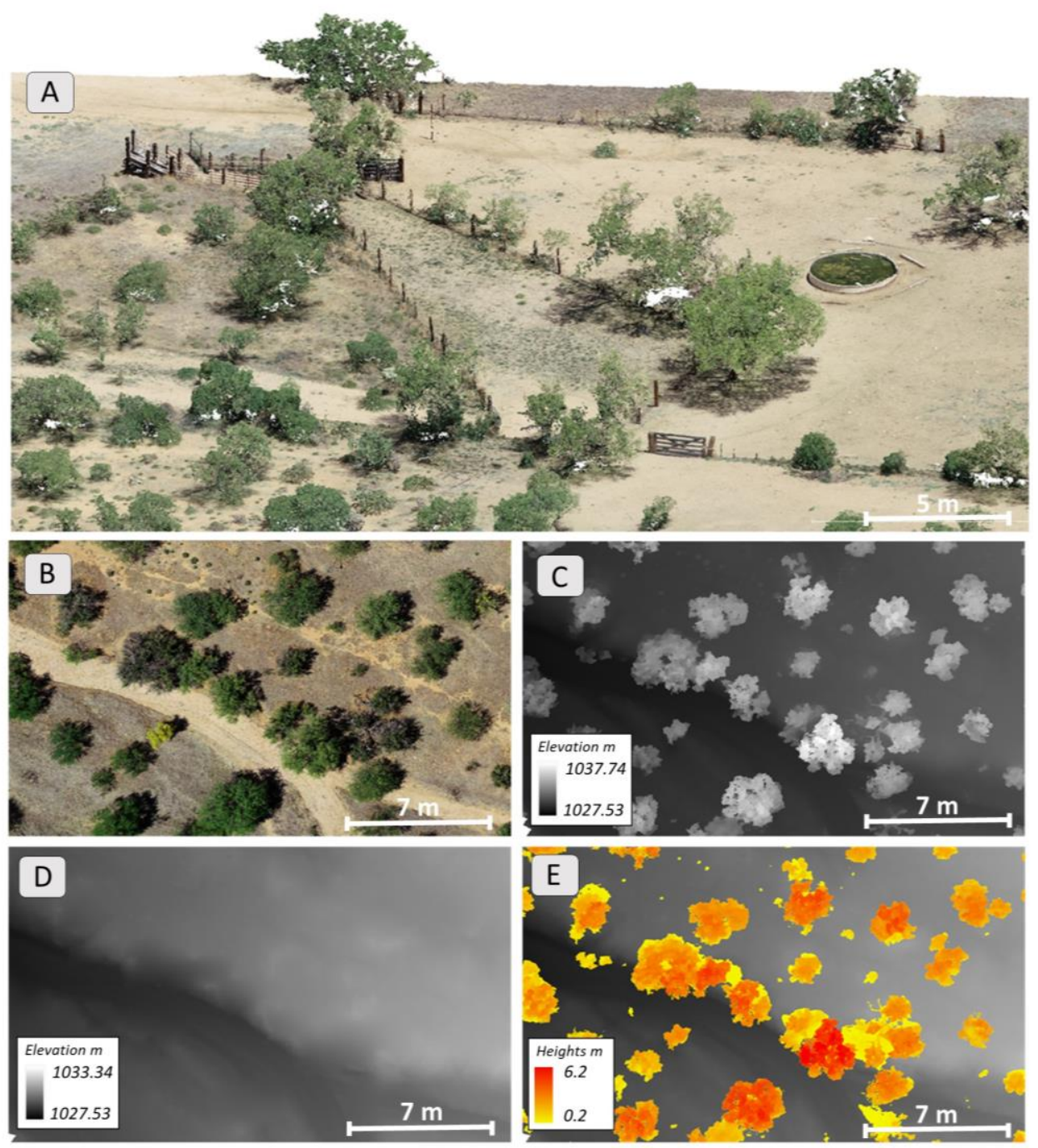

534 Fig. 3. Imagery products created from drone imagery, including A) Dense point cloud; B) True-color Orthomosaic; C) Digital surface model; D) Digital terrain model; and E) Vegetation height model. 

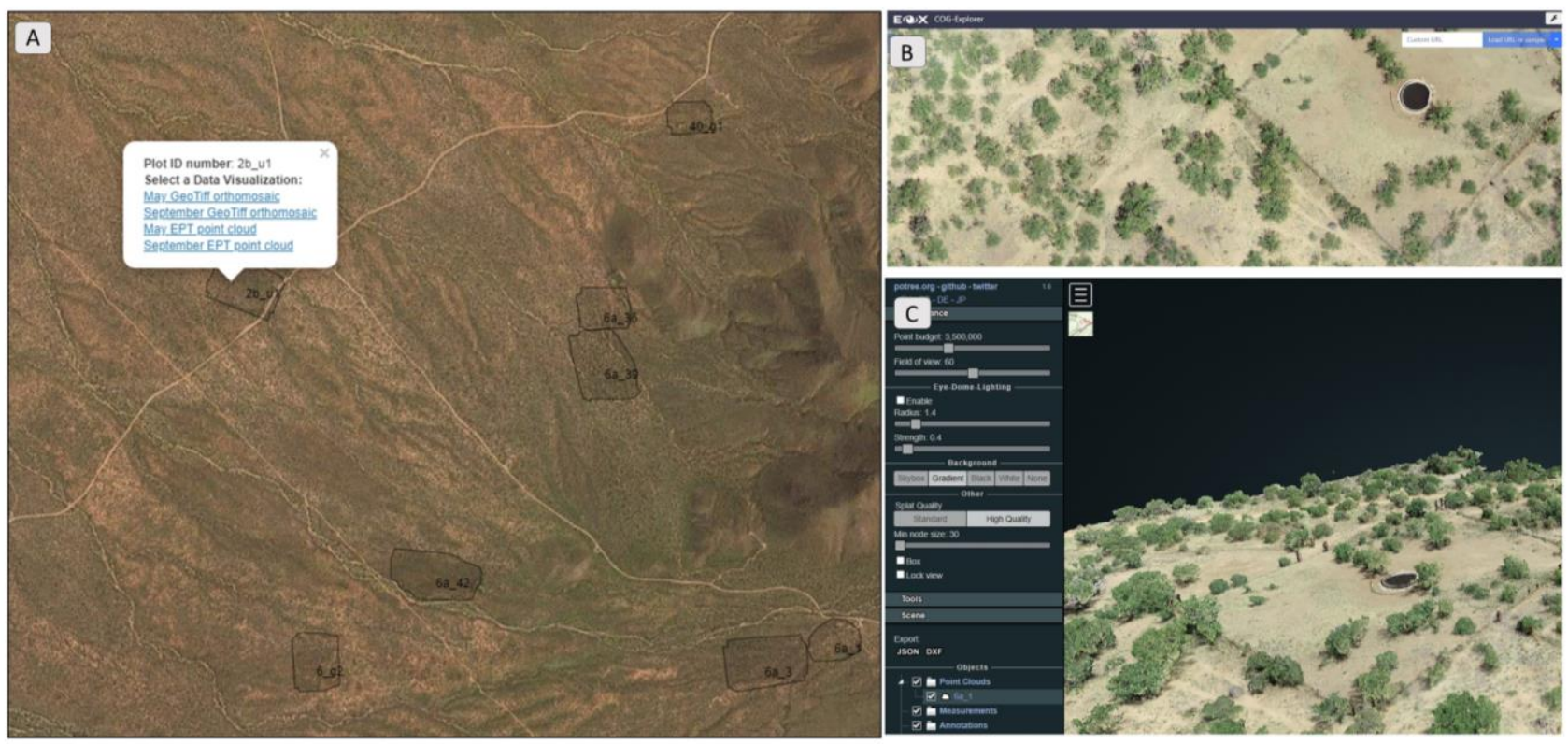

Fig. 4. A) We created an open-source Leaflet map to enable collaborators to view imagery products through a webbrowser (https://de.cyverse.org/....pending DOI). B) High-resolution orthomosiacs can be viewed with Eox COG

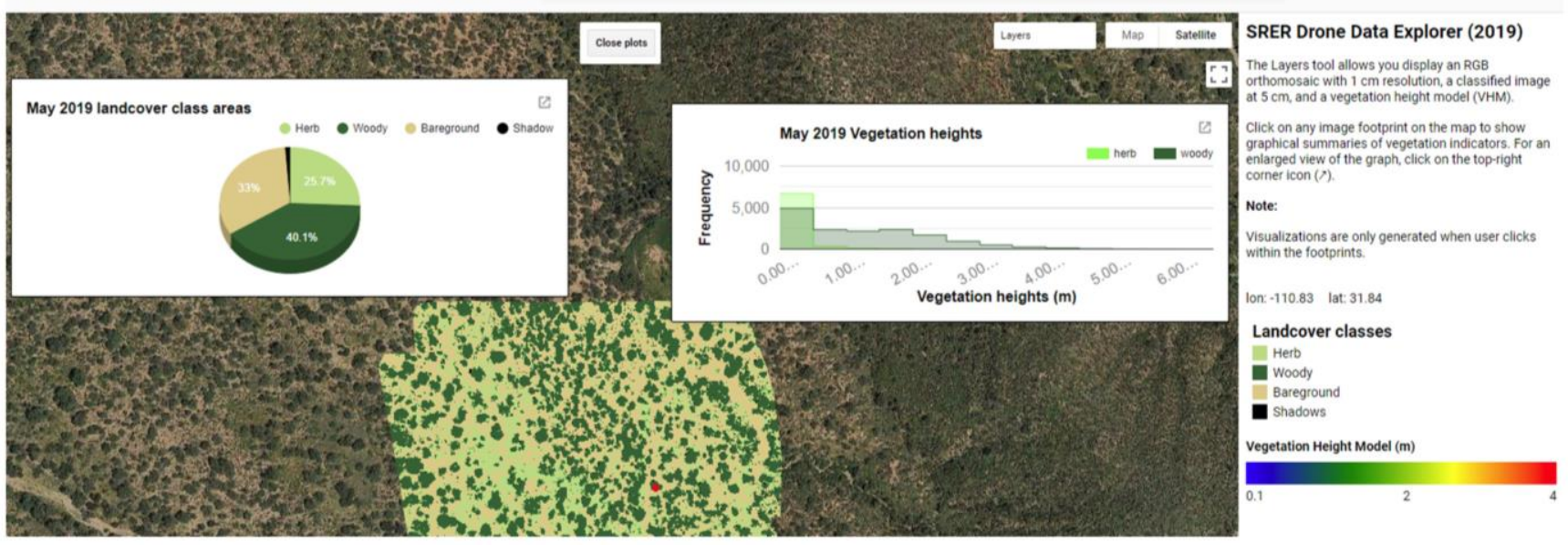

550 Fig. 5. We developed Google Earth Engine web-app showing classified maps, vegetation height models, and

551 indicator summaries for vegetation cover and heights. https://bit.ly/srer-drone-2019 